127. NARCISSUS ELEGANS (HAWORTH) SPACH (AMARYLLIDACEAE), CITA NUEVA PARA ESPAÑA CONTINENTAL

\author{
Joaquín RAMÍREZ LÓPEZ
}

Recibido el 15 de enero de 2007, aceptado para su publicación el 14 de febrero de 2007 Publicado "on line" en febrero de 2007

A new record for continental Spain, Narcissus elegans (Haworth) Spach (Amaryllidaceae)

Keywords. Narcissus elegans, Málaga, Spain.

Palabras clave. Narcissus elegans, Málaga, España.

Narcissus elegans (Haworth) Spach es una especie otoñal que siempre se consideró endemismo magrebí; su área se extiende por las zonas litorales y sublitorales de Libia,
Túnez, Argelia y Marruecos. En Europa, sólo se conocía del sur de Italia, y de las islas de Sicilia (Italia), y Mallorca (Baleares, España). Del sur de Italia y de Sicilia se

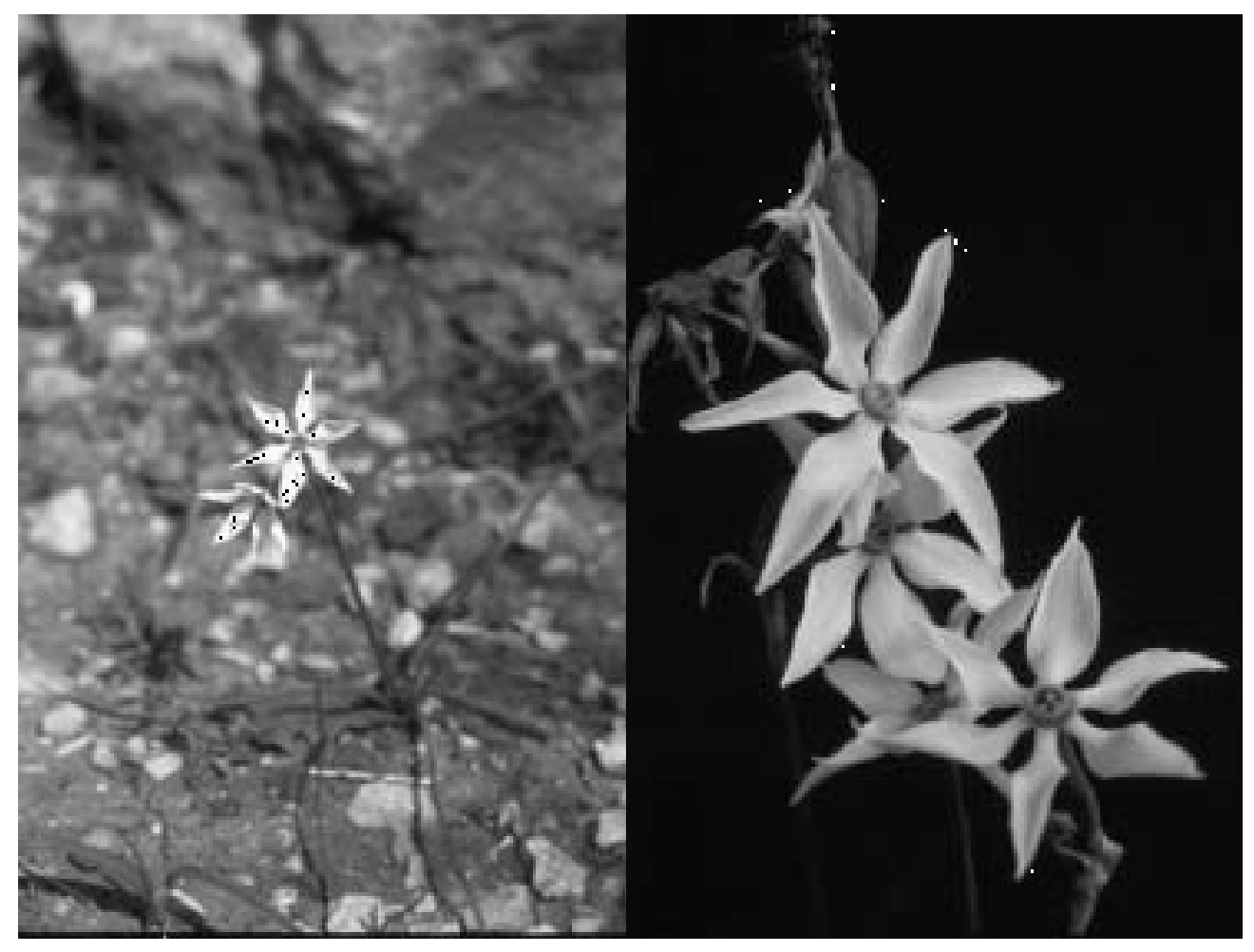

Figura 1. Narcissus elegans (Haworth) Spach: planta completa y detalle de las inflorescencias. 
conoce desde tiempos antiguos. De Mallorca, sólo conocemos la colección que hizo en 1935 Miss Cooper (K).

El paisaje de la localidad en la cual se ha localizado es agreste y mediterráneo, con interesantes matices geomorfológicos. E1 modulado kárstico desarrollado sobre las calizas, dibujan las más variada gama de fenómenos entre los que sobresalen las dolinas, torcas, simas, lapiaces, acanaladuras de disolución, etc.

La población actual estimada es de unas 1.000 plantas y la superficie potencial es de unos 500 metros cuadrados. Florece en octubre-noviembre y la hemos visto fructificada en enero. Presenta, a diferencia de $N$. serotinus, hojas y flores a la misma vez y la inflorescencia siempre es multiflora (fig. 1).

Málaga: Antequera, Villanueva de Cauche. Sierra de Camarolos: entre las poblaciones de Colmenar y Villanueva de Cauche (pedanía de Antequera), 30SUF78, 860-980 m, J. Ramírez López ,13-I-2007, (MAF 166 600); idem, 26-X-2005, (MGC 64458).

AGRADECIMIENTOS. La identificación del material fue confirmada por el Dr. Francisco Javier Fernández Casas.

Dirección del autor. Escritora Luciana Narváez, $\mathrm{n}^{\circ} \quad 3-4^{\circ}$, A. E-29011 Málaga (España) jrlmalaga@hotmail.com

\title{
128. UNA NUEVA COMBINACIÓN EN EL GÉNERO CAMPANULA L. (CAMPANULACEAE)
}

Gabriel BLANCA

\begin{abstract}
Recibido el 23 de febrero de 2007, aceptado para su publicación el 15 de marzo de 2007
\end{abstract} Publicado "on line" en marzo de 2007

A new combination in the genus Campanula L. (Campanulaceae)

Palabras clave. Campanula, Península Ibérica, nueva combinación.

Key words. Campanula, Iberian Peninsula, new combination.

Campanula willkommii Witasek es un taxón muy poco conocido que fue descrito para el núcleo central silíceo de Sierra Nevada (Witasek, 1902). Siete años después de su publicación, Pau (1909) lo consideró también como especie independiente, a la que denominó $C$. nevadensis Pau. En la mayoría de las obras consultadas se ha considerado sinónimo de $C$. hispanica Willk., ésta última subordinada con el rango 